\title{
Edukasi apoteker cilik terkait pengenalan obat kepada siswa kelas 5 SD Negeri Mangkura 1 Makassar
}

\author{
Sri Wahyuningsih ${ }^{1^{*}}$ \\ 1Universitas Megarezky, Makassar, Indonesia \\ DOI: https://doi.org/10.29303/indra.v2i2.132
}

\section{Article Info}

Received : 26-09-2021

Revised : 29-09-2021

Accepted: 30-09-2021

\begin{abstract}
Sources of information about drugs are pharmacists, but many people do not know the Pharmacist profession. This is causes problems not only in adults but in children. Lack of knowledge about drugs in children can lead to drug abuse. The purpose of this activity is to educate Young Pharmacists regarding the introduction of drugs and as an embodiment of drug awareness ambassadors from an early age. This activity has been carried out at SD Negeri Mangkura 1 Makassar with 54 participants from 5th-grade elementary school students. The method of implementing the activity begins with educating the pharmacist on delivering the Young Pharmacist material, singing the Young Pharmacist jingle, and continuing with a question and answer session regarding drug knowledge to elementary school students. This Young Pharmacist education activity got positive results for 5th-grade students of SD Negeri Mangkura 1 Makassar which was seen from the increase in student's knowledge about the Pharmacist profession and students were very enthusiastic about giving good choices or bad choices regarding the safety of drug use. In addition, two Young Pharmacist ambassadors were chosen as the embodiment of drug awareness ambassadors from an early age.
\end{abstract}

Keywords: Drugs Information, Education, Young Pharmacist.

Citation: Wahyuningsih, S. (2021). Edukasi Apoteker Cilik Terkait Pengenalan Obat kepada Siswa Kelas 5 SD Negeri Mangkura 1 Makassar. INDRA: Jurnal Pengabdian kepada Masyarakat, 2(2), 58-61. doi: https://doi.org/10.29303/indra.v2i2.132

\section{Pendahuluan}

Obat merupakan bahan yang sangat mudah ditemukan tetapi pengetahuan masyarakat tekait kesehatan dan terutama terhadap obat masih terbatas. Karena obat memiliki peranan penting dalam pelayanan kesehatan, maka obat harus selalu digunakan secara benar agar memberikan manfaat klinik yang optimal (Monica et al., 2019). Salah satu sumber informasi tentang obat adalah apoteker atau farmasis. Apoteker berperan dalam bidang kesehatan dengan memberikan Konsultasi, Informasi dan Edukasi (KIE) sehinga mengarahkan pasien untuk melakukan pola hidup sehat, dan melakukan monitoring. Sasaran pendidikan dan pelayanan kesehatan yang ditujukan kepada kelompok atau populasi umur tertentu sangat menentukan keberhasilan suatu program kesehatan (Sari \& Suswandari, 2016).

Masalah kesehatan berkaitan dengan penggunaan obat merupakan tugas apoteker sebagai salah satu tenaga kesehatan telah diakui eksistensinya di Indonesia melalui Peraturan Pemerintah No.51 tahun 2009 tentang Pekerjaan Kefarmasian (Pemerintah Republik Indonesia, 2019). Berdasarkan hasil survey ternyata masih banyak masyarakat yang tidak mengenal seorang apoeteker. Sehingga hal tersebut menimbulkan permasalahan terkait penggunaan obat. Masalah tersebut tidak hanya terjadi pada orang dewasa tetapi juga berkaitan dengan anak - anak (Yanti \& Vera, 2020). 
Anak-anak sering bersikap tidak patuh meminum obat hal ini dikarenakan mereka beranggapan bahwa obat memiliki rasa tidak enak dan pahit. Sehingga, orangtua terutama ibu sangat berperan untuk menjaga kepatuhan minum obat bagi anak-anak. Hal tersebut akan lebih mudah apabila pada diri anak juga ditumbuhkan kesadaran untuk patuh minum obat sejak usia dini. Selain itu, kurangnya pengetahuan anak mengenai obat yang benar dapat menyebabkan anak mudah terpengaruh untuk menyalahgunakan obat, terutama golongan narkotika dan obat terlarang (Yanti \& Vera, 2020).

Melalui apoteker cilik ini kita berusaha untuk mengenalkan profesi apoteker sebagai salah satu tenaga kesehatan yang memiliki keahlian dibidang penggunaan obat kepada masyarakat. Menurut (Satria, 2016) penting untuk bisa memberikan pengenalan terhadap dunia kesehatan pada anak-anak sejak mereka kecil, salah satunya melalui program apoteker cilik ini. Apoteker Cilik adalah sebuah gagasan untuk meningkatkan peran profesi Apoteker secara lebih real sejak usia dini. Inisiatif ini diharapkan mampu meningkatkan citra positif profesi apoteker di tengah masyarakat agar tercipta kondisi lingkungan yang menyehatkan untuk masyarakat (Octavia \& Aisyah, 2019).

Apoteker cilik dibentuk agar eksistensinya dapat dikenal seperti profesi dokter dengan program dokter ciliknya. Selain itu, untuk mengenalkan kegiatan kefarmasian kepada anak-anak di usia dini, sehingga dapat tercipta suasana sehat di lingkungan sekolah maupun dilingkungan rumah (Fahriati et al, 2020). Mindset masyarakat mengenai tanya obat tanya Apoteker dapat terwujud. Jumlah dan sebaran apoteker di Indonesia dinilai masih jauh dari kata ideal. Jumlah Apoteker teregistrasi di Indonesia berdasarkan data Komite Farmasi Nasiona (KFN) di tahun 2016-2017 sebanyak 67.594 dipandang masih belum layak untuk menunjang layanan dan perlindungan kesehatan masyarakat Indonesia secara baik (Fijriati, 2018).

Kondisi tersebut diperparah lagi dengan tidak meratanya sebaran apoteker hingga daerah terpencil. Jika dibandingkan dengan jumlah penduduk Indonesia dari data BPS Kependudukan yang mencapai 262 juta jiwa akan terlihat rasio apoteker dengan penduduk 1:3.900 artinya belum ideal sedangkan rekomendasi rasio ideal menurut WHO adalah 1:2.000. Jika dibandingkan di negara lain rasio di Indonesia jauh lebih rendah, Jepang (1:660), Thailand (1:1.000), Prancis (1:1.300), Amerika Serikat (1:1.430) dan Australia (1:1.700) (Fijriati, 2018).

Berdasarkan hal tersebut, maka perlu dilakukan kegiatan edukasi apoteker cilik terkait pengenalan obat untuk meningkatkan eksistensi Apoteker dan tugasnya sehingga pelaksanaan program
Apoteker Cilik dapat sebagai perwujudan kader sadar obat sejak dini. Selain itu, pengetahuan anak tentang obat semakin baik sehingga anak dapat ikut andil dalam menyampaikan informasi obat dan kepatuhan penggunaan obat secara umum kepada keluarga dan lingkungannya sejak dini.

\section{Metode}

Kegiatan edukasi apoteker cilik terkait pengenalan obat dilakukan dilaksanakan pada hari Sabtu, 12 Oktober 2019 di SD Negeri Mangkura 1 Makassar. Partisipan kegiatan apoteker cilik ini merupakan siswa kelas 5 SD. Pemilihan partisipan ini karena siswa kelas 5 SD dari segi usia dianggap sudah mampu menjadi kader sadar obat sejak dini sedangkan siswa kelas enam sedang mempersiapkan ujian dan siswa kelas empat ke bawah dianggap usianya masih tidak mampu untuk memahami materi.

Metode pelaksanaan kegiatan dimulai degan edukasi penyampaian materi apoteker cilik oleh Apoteker, menyanyikan jingle apoteker cilik, dan dilanjutkan sesi tanya jawab terkait pengenalan obat kepada siswa SD.

Penyampaian materi dilakukan dengan interaktif menggunakan power point. Selain itu juga disiapkan permainan terkait materi untuk peserta disertai hadiah menarik untuk pemenang. Dalam penyampaian materi disertai dengan pertanyaan yang jawabannya berupa pilihan good choices atau bad choices.

Proses monitoring dan evaluasi berdasarkan pertanyaan terkait prinsip keamanan penggunaan obat, seperti hanya minum obat dengan izin orang tua, jangan berbagi obat atau menggunakan obat orang lain, simpan obat dalam wadah aslinya dan di tempat yang aman, serta buang obat dengan benar. Setiap jawaban pertanyaan akan dibahas oleh apoteker untuk mengedukasi siswa kelas 5 SD Negeri Mangkura 1 Makassar sebagai apoteker cilik terkait pengenalan obat.

\section{Hasil dan Pembahasan}

Saat ini, pemberdayaan program pendidikan kesehatan dan pelayanan kesehatan di usia dini khususnya di tingkat sekolah dasar telah mengalami perkembangan. Supaya didapatkan hasil yang sempurna, program pemberdayaan pendidikan kesehatan dan pelayanan tersebut perlu juga kehadiran apoteker cilik yang kedepannya dapat saling beriringan. "Apoteker Cilik" adalah kegiatan introduksi profesi kefarmasian kepada anak-anak usia sekolah agar dapat mengenal dan menimbulkan minat anak terhadap profesi kefarmasian. Sosialisasi tentang dunia kesehatan kepada anak-anak terutama profesi apoteker ini diharapkan dapat meningkatkan pengetahuan tentang kesehatan pada umumnya dan 
penggunaan obat yang tepat khususnya (Octavia \& Aisyah, 2019).

Kegiatan ini berupa edukasi apoteker cilik terkait penggunaan obat yang mengangkat tema bersama Apoteker Mengenali Obat Sejak Usia Dini, sehingga sasaran kegiatan ini bagi para siswa SD di sejumlah sekolah yang telah dipilih. Kegiatan edukasi ini disesuaikan dengan karakteristik siswa dan dibuat semenarik mungkin dengan aktivitas yang kreatif dan inovatif melalui permainan, diskusi interaktif dan penampilan seni kreatif. Agar mampu menarik minat siswa untuk mengenal lebih jauh penggunaan obat sejak usia dini.

Kegiatan edukasi apoteker cilik kepada siswa kelas 5 SD Negeri Mangkura 1 Makassar dihadiri oleh 54 siswa dan berjalan lancar. Penting bagi siswa sekolah dasar untuk belajar tentang kesehatan. Sebagian besar siswa yang telah belajar tentang kesehatan mampu meningkatkan pengetahuan mereka tentang kesehatan dan obat-obatan, sehingga mereka lebih tepat dalam mengkonsumsi obat, yaitu sesuai dengan indikasi dan kondisinya.

Kegiatan ini diawali dengan perkenalan oleh siswa dengan menyebutkan cita-citanya. Ternyata masih sedikit siswa yang memiliki cita-cita sebagai apoteker. Kegiatan selanjutnya yaitu sesi diskusi terkait "Siapa itu Apoteker?". Dari hasil diskusi tersebut, sudah ada lima siswa yang mampu menyebutkan pengertian Apoteker bedasarkan PP 51 tahun 2019 tentang Pekerjaan Kefarmasian

Kegiatan edukasi apoteker cilik telah dilakukan di beberapa sekolah dasar. Menurut Fahriati et al. (2020), siswa-siswi Madrasah Ibtidaiah Negeri (MIN) 2 Kota Tangerang Selatan telah memiliki program kesehatan sekolah dengan mengadakan dokcil atau dokter cilik, namun belum memiliki program apocil. Siswa-siswi kurang mengenal profesi apoteker sebagai salah satu tenaga kesehatan dan sumber informasi tentang penggunaan obat. . Hasil ini berbeda dengan edukasi kegiatan di SD Negeri Mangkura 1. Dengan adanya program kesehatan lainnya seperti Dokter Cilik yang telah memberikan pemahaman terkait kesehatan. Sehingga, siswa sudah tidak asing lagi dengan istilah apoteker walaupun jumlah siswa yang mengetahui profesi apoteker masih kurang dan belum ada program Apoteker Cilik di SD Negeri Mangkura 1.

Setelah sesi tanya jawab dilanjutkan dengan menyanyikan jingle apoteker cilik. Jingle ini berisi edukasi terkait pengenalan obat untuk cerdas menggunakan obat sedari dini. Jingle apoteker cilik ini berisi ajakan kepada siswa SD untuk menjadi apoteker cilik dan tidak salah dalam penyalahgunaan obat seperti pada gambar 2 .

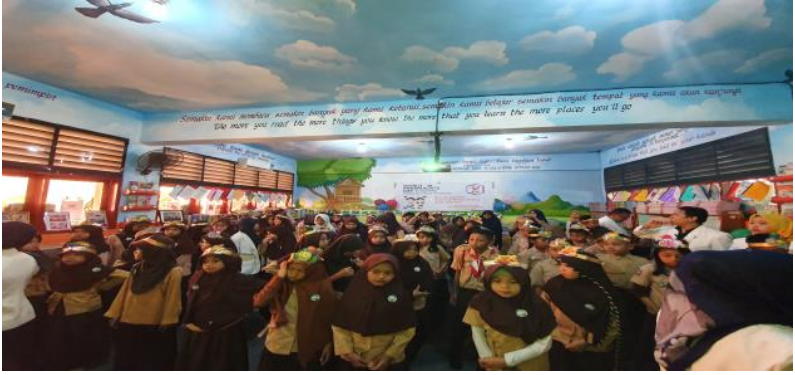

Gambar 1. Suasana Edukasi Apoteker Cilik

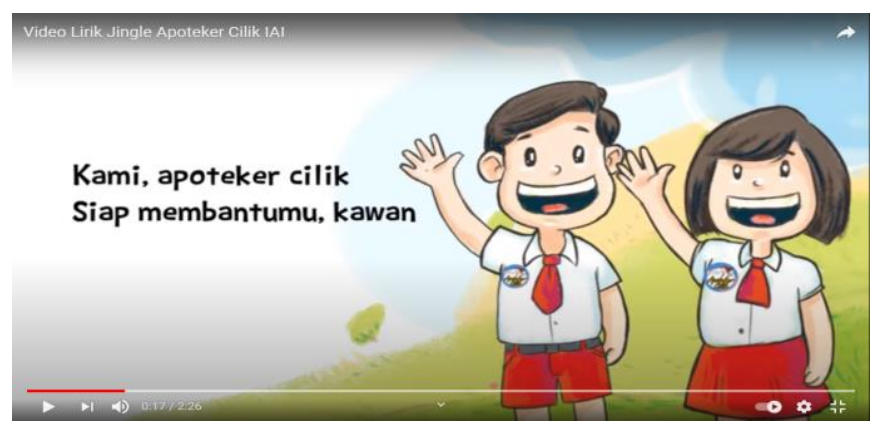

Gambar 2. Jingle Apoteker Cilik

Penyampaian materi edukasi apoteker cilik dsertai dengan pertanyaan yang jawabannya berupa pilihan good choices atau bad choices. Apabila siswa menjawab good choices maka angkat mengangkat kertas bergambar senyum, sebaliknya apabila jawabaan siswa bad choices maka akan mengangkat kertas bergambar sedih seperti gambar 3 .

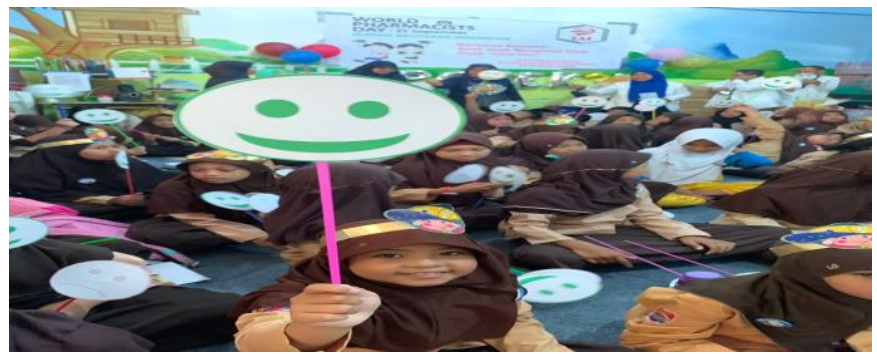

Gambar 3. Pilihan jawaban good choice atau bad choice

Jawaban pertanyaan akan dibahas oleh fasilitator untuk menjelaskan terkait keamanan penggunaan obat, seperti hanya minum obat dengan izin orang tua, jangan berbagi obat atau menggunakan obat orang lain, simpan obat dalam wadah aslinya dan di tempat yang aman, serta buang obat dengan benar. Berdasarkan hal ini dapat dilihat siswa sangat antusias menjawab pertanyaan dengan baik dan benar. Siswa yang menjawab jawaban benar akan diberikan hadiah berupa stiker yang ditempelkan di wajah.

Berdasarkan hasil kegiatan yang telah dilakukan maka terpilih dua orang siswa sebagai duta apoteker cilik sebagai perwujudan kader sadar obat sejak dini. Siswa yang menjadi duta ini diharapkan 
mampu menjadi mitra apoteker pengetahuan anak tentang obat semakin baik sehingga anak dapat ikut andil dalam menyampaikan informasi obat dan kepatuhan penggunaan obat secara umum kepada keluarga dan lingkungannya sejak dini.

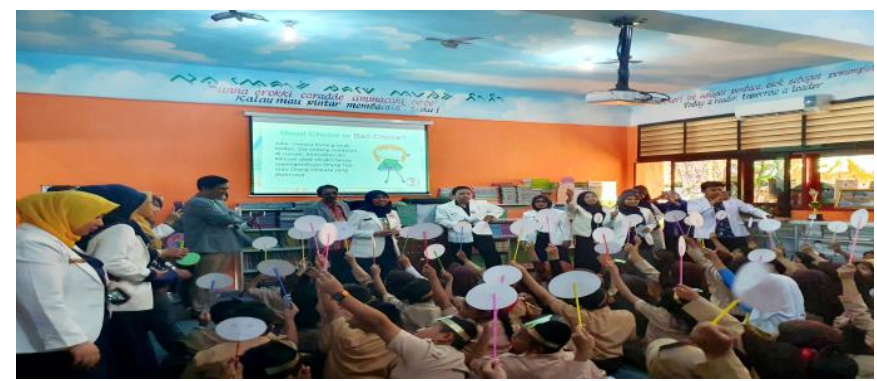

Gambar 4. Edukasi Pengetahuan Obat

\section{Simpulan}

Kegiatan edukasi apoteker cilik ini mendapat hasil yang positif bagi siswa kelas 5 SD Negeri Mangkura 1 yang terlihat dari peningkatan pengetahuan siswa tentang profesi apoteker dan siswa sangat antusias memberikan pilihan jawaban baik dan buruk terkait keamanan penggunaan obat. Selain itu terpilih dua duta apoteker cilik sebagai perwujudan kader sadar obat sejak dini.

\section{Daftar Pustaka}

Fahriati, A. R., Nurihardiyanti, Maelaningsih, F. S., Aulia, G., Sari, D. P., Werawati, A., Fadhilah, H., Ismaya, N. A., Melizsa, Nadya, A. R. I., Sayyidah. (2020). Penyuluhan dan Pengenalan Profesi Apoteker Kepada Siswa Sekolah Dasar di MIN 2 Tangerang Selatan. Prosiding Senantias, 1(1), 687-694. http://openjournal.unpam.ac.id/index.php/Senan /article/view/8301/5334

Fijriati, L. (2018, April 29). Apoteker Cilik, Pendidikan Sadar Obat Sejak Dini. Pantura News. https://www.panturanews.com/index.php/pantur anews/baca/251566/29/04/2018/apoteker-cilikpendidikan-sadar-obat-sejak-dini

Monica, B., Mulyanto, F., Rahmi, A. (2019). Penggunaan Obat Sejak Dini (Tanya Lima O) Kepada Siswa/i SMA Negeri 1 Sukamara. Jurnal Borneo Cendekia, 3(1), 67-70. <http://journal.stikesborneocendekiamedika.ac.id/ index.php/jbc/article/view/136

Octavia, D. R., \& Aisyah, M. (2019). Pelatihan Apoteker Cilik Siswa Sekolah Dasar Dalam Upaya Penggunaan Obat Yang Tepat Di Lamongan. Journal of Character Education Society (JCES), 2(2), 1-10. https://doi.org/10.31764/jces.v2i2.1482
Pemerintah Republik Indonesia. (2019). Peraturan Pemerintah Republik Indonesia No. 51 Tahun 2019 Tentang Pekerjaan Kefarmasian. Indonesia. Jakarta: Indonesia

Sari, N. K. \& Suswandari, M. (2016). Effektivitas Program Apoteker Cilik (Apcil) terhadap Pengetahuan Tanaman Obat Tradisional Keluarga Di Sekolah Dasar Negeri 2 Sukoharjo Tahun Ajaran 2015/2016. Jurnal Pendidikan, 25(1), 35-40.

Satria. . (2016, Januari 04). Dosen UGM Gagas Apoteker Cilik. UGM. https://www.ugm.ac.id/id/berita/10984-dosenugm-gagas-apoteker-cilik

Yanti, S., \& Vera, Y. (2020). Penyuluhan Tentang Cara Penggunaan Obat Yang Baik dan Benar di Desa Manunggang Jae. Jurnal Education and Development, 8(1), 26-28. https://doi.org/10.37081/ed.v8i1 